\title{
Annotation
}

\section{Ground Breaking Landmark Case on Environmental Quality Standards?}

\author{
The Consequences of the cJEU 'Weser-judgment' (C-461/13) for Water Policy \\ and Law and Quality Standards in EU Environmental Law
}

\author{
H.F.M.W. van Rijswick \\ University of Utrecht, The Netherlands \\ h.vanrijswick@uu.nl \\ Chris W. Backes \\ University of Maastricht, The Netherlands \\ chris.backes@maastrichtuniversity.nl
}

\section{The Long and Winding Road to Clarity}

The Water Framework Directive (hereafter: WFD) is a major step forward in integrated water resource management. Its innovative and adaptive approach which pays specific attention to the protection of aquatic ecosystems, and the great emphasis on involvement of the public in all stages of the policy process was a source of inspiration for many countries across the world. The river basin approach as the main scale for water management follows the UNECE Water Convention ${ }^{1}$ and is logical from a water management perspective. This approach has to be embedded in the existing regulatory framework with a patchwork of water related Directives and relevant Directives in other fields of environmental law. Focussing on the achievement of a good status of all

1 The Convention on the Protection and Use of Transboundary Watercourses and International Lakes (Water Convention) was adopted in Helsinki in 1992 and entered into force in 1996. United Nations, Treaty Series, vol. 1936, p. 269. 
European waters the relationship with other policy fields became clear. One should for example realize that many European waters overlap with Natura 2000 sites, in the Netherlands for more than $80 \%$. Important causes for water pollution stem from agriculture, urban wastewater and air pollution. Floods are often caused by decisions in land use planning which do not take the effects on water into account. Also institutional arrangements were needed because river basin management needs competent authorities that operate at a different scale and level than the traditional Member States, regions, provinces and municipalities. Protecting ecosystems asks for quality standards other than those prevalent in more classical EU environmental Directives, which were better suited for chemical pollution. It is clear that such a large transition goes with uncertainties and lessons to learn. This does not mean at all that the approach taken is not a good way forward and necessary for sustainable and equitable water management.

At the same time another development took place: The classical way of regulation by setting goals and standards and describing in a detailed way which policy instruments the Member States had to apply was regarded unsuitable to manage water in the 21st century. Many Member States nowadays put more emphasis on subsidiarity, claiming more policy discretion on how they want to tackle water problems and enabling them to take regional differences into account. ${ }^{2}$ This new approach in environmental legislation also effected recent developed water legislation. It puts much more emphasis on public participation and increases the role of economic instruments. ${ }^{3}$ Also the design of the legislation has been changed: the use of framework directives has increased. The WFD is an important example of this development. The WFD focuses on planning and a programmatic approach, thus not only providing Member

2 Keessen, A.M., Runhaar, H.A.C., Schoumans, O.F., Van Rijswick, H.F.M.W., Driessen, P.P.J., Oenema, O., and Zwart, K.B., The need for flexibility and differentiation in the protection of vulnerable areas in EU environmental law: the implementation of the Nitrates Directive in the Netherlands, Journal for European Environmental and Planning Law, JEEPL 8.2 (2011), p. $162-185$.

3 J. Adshead, Public participation, the Aarhus Convention and the Water Framework Directive, Journal of Water Law, volume 17, 2006, p. 185 et seq.; R. Fairley et al, Riding the new wave of European water law: how member states are tackling the Water Framework Directive, EEE LR, vol.11, 2002, nr. 8/9, p. 232-239; W. Howarth, Aspirations and Realities under the Water Framework Directive: Proceduralisation, Participation and Practicalities, Journal of Environmental Law 2009-3, p. 391-417.; M. Lee, Law and Governance of Water Protection Policy, in: J. Scott (ed), Environmental Protection, European law and governance, Oxford, Oxford University press, 2009. 
States more flexibility, ${ }^{4}$ but also enabling them to insert policy instruments from different policy fields into programmes of measures. The idea is that this will make water law more effective because, depending on the causes for specific water problems, the most effective policy instrument can be chosen, even if it stems from another field than water legislation. So - in theory - a truly integrated approach can be realized.

The approach in the WFD is based on an adaptive six year policy cycle starting with 1) an analysis of human and natural impacts on current river basins, followed by 2) setting goals and standards at the EU and the national level and proceeding with 3) the plans and programmes that exists of the policy instruments that will be used to meet the goals and which are accompanied by 4) an obligation to develop a sophisticated monitoring network, finally leading to 5) revised plans and programmes for the next planning period. This approach should be able to improve Europe's river basins and aquatic ecosystems in the period between the years 2000 and 2027.

However, things are never as easy as they look at first sight. In the last fifteen years it became clear that there was a tension between the flexibility asked for by the Member States and the effectiveness of water management with regard to the achievement of the environmental goals. The implementation was also hampered by the fact that the text of the WFD was far from clear and left Member States with many questions on how to interpret the obligations following from the Directive. ${ }^{5}$ This led to different implementation strategies in the Member States and thus legal uncertainty and different approaches across the EU. In the last years it became clear that the WFD did not lead to the improved water quality that was expected. ${ }^{6}$ The first WFD cycle operated from 2009 to 2015 , and during this cycle it is estimated that the number of surface

4 S. van Holten and H.F.M.W. van Rijswick, The consequences of a governance approach in European Environmental Directives for flexibility, effectiveness and legitimacy, in: M. Peeters and R. Uylenburg (eds.), EU environmental legislation: Legal perspectives on regulatory strategies, Edward Elgar Publishing, 2014, p. 13-47.

5 See Ekkehard Hofmann (ed), Wasserrecht in Europa, Nomos, Baden Baden 2015; L. Baaner, Programmes of Measures under the Water Framework Directive - A Comparative Study, Nordic Environmental Law Journal, 2011/1, p. 31-52; H. Josefsson, Good Ecological Status, Advancing the Ecology of Law, diss, Uppsala Universitet, 2015. See also several publications of Henrik Josefsson, Lasse Baaner, Helle Tegner Anker and Lena Gipperth from the Scandinavian region and A.M. Keessen et al, European River Basins: Are They Swimming in the Same Implementation Pool?, Journal of Environmental Law, 22:2 (2010), 197-221 which paper was a result of the ongoing cooperation of water law specialists throughout Europe in the European network for water Law/Reseau d' eau.

6 See http://ec.europa.eu/environment/water/water-framework/impl_reports.htm. 
water bodies in "good" state will increase from $43 \%$ to $53 \% .^{7}$ That is not an impressive result at all when one realises that $\mathrm{EU}$ water law exists since the seventies of the last century and that most requirements from the WFD were already part of older water directives.

In recent case law on the cost recovery obligation of Article 9 WFD the Court gave a first impression on how the Member States should interpret the WFD. ${ }^{8}$ But the most important provision of the WFD - Article 4 with its environmental objectives - still remained unclear even though it is crucial for a proper understanding of the WFD system. The Weser case ${ }^{9}$ finally sheds some light on the legal meaning of not only the environmental obligations, but also on the system of the WFD as a whole.

It is worth noting that the decision in case C-461/13 was decided by the Grand Chamber, which nowadays is quite rare and only done in cases of exceptional importance. This surely underlines that the questions put forward by the German Bundesverwaltungsgericht (BVerwG) concern some of the most fundamental questions of the WFD and possibly beyond. ${ }^{10}$

\section{Doubts of the German Judges and Assurance of the European Court (Questions and Answers)}

\subsection{The Case}

Before diving into the questions put forward by the BVerwG and discussing the answers of the CJEU, we will turn shortly to the river Weser, north of Bremen. The questions on the meaning of Article 4 (1) WFD were raised in a case pending at the BVerwG and concern a planning permission for three projects for

7 See http://ec.europa.eu/environment/water/water-framework/impl_reports.htm.

8 See P.E. Lindhout \& H.F.M.W. van Rijswick, The effectiveness of the principle of recovery of the costs of water services jeopardized by the European Court of Justice, JE EPL, 2015-1, pp 78-92 and the JEEPL special issue on cost recovery with contributions from Germany, Portugal and the Netherlands, see Petra Lindhout, Moritz Reese and Marleen van Rijswick, Editorial in the special issue on Cost recovery for water services in European water law, JEEPL 10.4 (2013) 305-307, DOI 10.1163/18760104-01004009.

9 Judgement of the Court (Grand Chamber) in Case C-461/13 of 1 July 2015; Bund für Umwelt und Naturschutz Deutschland eV versus Bundesrepublik Deutschland, and as joined party Freie Hansestadt Bremen.

10 W. Durner, Wasservertiefung muss bindende Vorgaben der WRRL einhalten, DVBl. 2015, 1049 qualifies the questions which were put forward as "the most discussed questions of interpretion of the whole water law in Germany” ('die meistdiskutiersteste Auslegungsfrage des gesamten Wasserrechts'). 
a further deepening and developing of the river Weser. Both developer and permitting authority were federal agencies. The aim of the works was to enable larger container vessels to reach the port of Bremerhaven irrespective of the tide, and to reach Bremen and other ports more upstream depending on the tide. Implementation of the projects at issue involves initial and regular dredging of the riverbed in the channels. Most of the dredged material arising from the development and from maintenance of the river is proposed to be discharged into the Outer and the Lower Weser at locations that have already been used for that purpose in the past. Furthermore, current speeds of water flows will increase on a rising tide and on an ebb tide, tidal high water levels will rise, tidal low water levels will fall, salinity will increase in parts of the lower Weser, the brackish water border in the lower Weser will move upstream and, finally, silting-up of the river bed will increase outside the navigable channel. To sum up, the project will have significant effects on the status of the water body (water quality and water quantity) which for the most parts are classified as heavily modified water bodies within the meaning of Article 2(9) of the WFD.

The permitting authority considered that the present status of certain heavily modified water bodies of the Weser river basin would tend to be adversely modified by the effects of the development projects at issue. However, this modification would, according to the German authorities, not result in 'deterioration' of the water body within the meaning of the WFD. The reason for this is that, according to the authority, a deterioration within a status class is not to be regarded as a deterioration of the ecological potential or the status of the water body concerned and therefore the authority concluded that deterioration within the meaning of the Directive was not to be expected.

Neither the judgment of the BVerwG nor the conclusion of the Advocate General announce any decision of a lower (district) court. The reason for this is that the German Federal Administrative Court (BVerwG) is the competent court of first (and last) instance as to permitting of certain very large infrastructure projects - including major constructions on federal waterways, according to section $5^{\circ}$ para 1 No. 6 Verwaltungsgerichtsordnung.

\subsection{The Questions Put Forward}

The German BVerwG asked four questions:

(1) Is Article 4(1)(a)(i) of Directive 2000/60 [...] to be interpreted as meaning that the Member States must - unless a derogation is granted — refuse to authorise a project if it may cause a deterioration in the status of a body of surface water, or is that provision merely a statement of an objective for management planning? 
(2) Is the term "deterioration of the status" in Article 4(1)(a)(i) of Directive $2000 / 60$ to be interpreted as covering only detrimental changes which lead to classification in a lower class in accordance with Annex $\mathrm{v}$ to the Directive?

(3) If the second question is to be answered in the negative: under what circumstances does "deterioration of the status" within the meaning of Article 4(1)(a)(i) of Directive 2000/6o arise?

(4) Are the provisions of Article 4(1)(a)(ii) and (iii) of Directive 2000/60 to be interpreted as meaning that the Member States must - unless a derogation is granted - refuse to authorise a project if it jeopardises the attainment of good surface water status or of good ecological potential and good surface water chemical status by the date laid down by the Directive, or are those provisions merely a statement of an objective for management planning?'

The CJEU merged questions 1 and 4 as well as questions 2 and 3. By doing so, the Court did not explicitly differentiate between the restraint to allow a 'deterioration of the status' of a water body and the goal of attaining a good status of surface waters. Instead, the Court distinguished two main themes the order of which we will take over in the following. The first theme concerns the relationship between water quality norms and plans, programmes, projects and authorizations. Are these standards only goals for management planning or are they, more or less, binding for concrete authorizations of projects and permitting decisions? The second theme concerns the way the standards have to be applied. What does 'no deterioration' mean and which exceptions are possible? Elaborating on the first topic, the Court may implicitly have given an answer to another question which has not (explicitly) been brought forward by the German Court, which nevertheless is important for water policy and law in practice: do the quality standards - just as the general environmental objectives - apply to all waters whether they are designated or not or do they only apply to designated water bodies. We will come back to this question when dealing with the first theme.

\subsection{The Scope of the Quality Standards ex Article 4 (1) WFD}

Within the EU, the views on the legal scope and meaning of environmental quality standards - as one of the most central regulatory instrument(s) of the WFD - are very diverse. According to German and Dutch authorities, the quality standards of Article 4 (1) only relate to river basin management plans and the Member States' programmes of measures for water. Therefore, they are not applicable as testing criteria for the approval of individual projects. 
The German authorities follow an approach that leads to the opinion that Article 4 (1) WFD does not prohibit deterioration, but only requires the adoption of measures aiming to prevent deterioration. Many Dutch water authorities advocated the same opinion, although this was not the way the WFD was finally implemented. The Dutch Government was convinced that the Member States have a large range of policy discretion when implementing the quality standards. Therefore, in the Netherlands, an approach was chosen which focusses on flexibility as regards their actual implementation and allows, requires even, a 'programmatic' approach. This means that in the Dutch legal context quality standards have to be taken into account only when a programme of measures is established. Other countries, like the UK and Poland take a stricter view and think that the standards on the basis of Article 4 (1) WFD also have to be applied to decisions on concrete, individual projects. ${ }^{11}$ In earlier comparative research on the implementation of the WFD in the Netherlands, Luxembourg, Belgium, Germany, France, England and Wales, Denmark, Italy, Romania, Spain and Portugal, we found similar disagreements on the meaning of Article 4 (1) WFD. ${ }^{12}$ Although not all implementation legislation had come into force at the moment of the research (2009), it became clear that Members States had different opinions on whether the environmental objectives of Article 4 WFD should be regarded as obligation of results or best practices, whether no-deterioration refers to all deterioration or only applies when a water body would shift to a lower class. Furthermore there are large differences between the amount of and selection criteria for water bodies that have been designated as artificial or heavily modified water body and the way external integration with other policy fields - agriculture, spatial planning, nature conservation - has been organised.

Following its Advocate General, the ECJ is quite clear on the questions related to the no-deterioration principle and the relationship between environmental requirements and policy instruments in the programme of measures. The prohibition of deterioration of the quality of a water body and the obligation to ensure a good water status by the year 2015 are binding requirements and not only goals for management plans. Environmental requirements and quality standards apply to the whole process of implementation of the WFD, in particular Articles 3, 5, 8, 11 and 13 and Annex v WFD. Hence, they also have to be applied on request for permits to allow a certain use of water. Furthermore, these standards must be applied strictly and do not allow flexibility or derogations other than those mentioned in the Directive itself.

11 Conclusion AG 23 October 2014, C-461/13, point 33.,

12 A.M. Keessen et al, European River Basins: Are They Swimming in the Same Implementation Pool?, Journal of Environmental Law, 22:2 (2010), 197-221. 
The Court came to this conclusion by using textual arguments, referring to the history of the WFD, analysing the structure of the WFD and relying on its purpose and aims. Hence, the CJEU used all classical methods of interpretation of written legal norms. A first argument concerns the wording of Article 4 (1) WFD. The Court stresses that the words 'shall implement' demonstrate the binding force of this provision. Furthermore, Article 4 (1) (a) obliges the Member States to 'implement the necessary measures to prevent deterioration' when 'making operational the programmes of measures specified in the river basin management plans'. Hence, the prohibition to allow deterioration does not only apply to the management plans and to the programmes of measures determined on the basis of these management plans, but also to the measures necessary to implement these programmes, e.g. permitting decisions and project authorizations. As the Court acknowledges, this textual interpretation is not entirely compelling. It only 'supports' the conclusions of the Court. Therefore, in the following, the Court refers to 'the ultimate objective' of the Directive, as laid down in its preamble and in Article 1 (a) and to its history. An important argument relates to the structure of the whole WFD. A series of provisions, in particular Articles 3, 5, 8, 11 and 13 and Annex v, serve to enable the Member States to implement measures in order to prevent deterioration and ensure a good status of all water bodies in 2015, which are to be seen as the main requirements of the Directive. Hence, these main obligations have 'binding effects, once the ecological status of the body of water concerned has been determined, at each stage of the procedure prescribed by that Directive' (point 43). This systematic argument seems to be essential in the reasoning of the Court. Yet, it is not compelling. One could also argue that, since the WFD does not explicitly determine that the aim to prevent deterioration is a binding criterion when applying the more concrete instruments mentioned in other provisions of the Directive, it is therefore up to the Member States to choose how they ensure that the aims of the Directive are met. One could also refer to subsidiarity at this point. However, the fact remains that the Court does not follow this route but decides that the main obligations of Article 4 (1) are to be seen as binding criteria for the application of all other instruments prescribed in the Directive in this way giving a clarification of the Directive which surely will increase its effectiveness.

Another systematic, more striking, argument relates to the derogation clause in Article 4 (7) WFD. According to Article 4 (7) 'Member States will not be in breach of this Directive when failure [...] to prevent deterioration [...] is the result of new modifications to the physical characteristics of a surface water body or alterations to the level of bodies of groundwater and all practicable 
steps have been taken to mitigate the adverse impact on the status of the body of water concerned [...]'. The CJEU stresses that permitting new projects may result in a failure to comply with the main objectives. That is obviously true. From that, the CJEU infers that therefore 'it is impossible to consider a project and the implementation of management plans separately'. That argument holds true if the prohibition to allow any deterioration is absolutely strict and absolute in time and even short periods of worsening are forbidden. If however short periods of limited worsening would be allowed, the reasoning of the Court would not be compelling. As we will see below (par. 2.3.2), the Court concludes that the prohibition of deterioration is indeed very strict and absolute in time. Taking that as a point of departure, it is compelling that the prohibition to deteriorate is a binding testing criterion for all permits which may have an influence on the quality status of surface waters.

The CJEU summarizes its line of reasoning in point 50 of the judgment: '[...] The obligation to prevent deterioration of the status of bodies of surface water remains binding at each stage of implementation of Directive 2000/60 and is applicable to every surface water body type and status for which a management plan has or should have been adopted. The Member State concerned is consequently required to refuse authorisation for a project where it is such as to result in deterioration of the status of the body of water concerned or to jeopardise the attainment of good surface water status, unless the view is taken that the project is covered by a derogation under Article 4(7) of the Directive.' This conclusion concerns question 1 of the BVerwG, relating to Article 4(1)(a) (i) of the Directive. The main arguments for this line of reasoning relate to the prohibition of deterioration and its relation to other provisions of the Directive. However, in the following point (51), the Court extents this conclusion without further reasoning to the requirement of ensuring a good quality status by the year 2015. Unless derogation is possible, the Member States are required '...to refuse authorisation for an individual project where it may cause a deterioration of the status of a body of surface water or where it jeopardises the attainment of good surface water status or of good ecological potential and good surface water chemical status by the date laid down by the Directive'. However the requirements of non-deterioration (Article 4(1)(a)(i)) and achieving a good quality status (Article 4(1)(a)(ii and iii)) are quite different. The requirement to ensure a good quality status does not apply at all times, but only at the end of 2015. It allows that the quality status may become worse before the end of 2015 or may fluctuate before this date as long as the inter-environnement doctrine is taken into account. According to this doctrine, Member States must, during the period for implementation of a directive, 'refrain from taking any measures 
liable seriously to compromise the result prescribed. ${ }^{13}$ Hence the prohibition of deterioration, which must be applied with at all times, leaves little room for compensatory measures when permitting a project with detrimental effects on the status of a water. This is different for the requirement to ensure a good quality status which leaves considerable room for "adverse" projects as long as they are flanked by sufficient compensatory measures. These differences should be kept in mind despite the decision of the CJEU to merge questions 1 and 4 of the BVerwG and to not explicitly address and accentuate the differences. The practical consequences of the judgment on the requirement of good status may be quite limited. In practice it is much easier to prove that a certain project or activity will lead to (a slight) deterioration than proving that it will jeopardize the attainment of a good status of a surface water at a certain date. One could think that this question will lose its relevance within the next months as the end of 2015 is approaching quickly. However, due to derogations on the basis of Article 4 (4), the date to ensure a good quality status often is later than 2015 .

\subsection{No Deterioration?}

The second topic discussed by the ECJ concerns the content of the prohibition to allow deterioration of surface waters. This topic was brought forward in questions 2 and 3 of the BVerwG.

A main issue discussed over the last decade in European water law and policy was whether the WFD would forbid any worsening of the quality of water bodies at all or only prohibit changes which would lead to a lower status class of the water body concerned..$^{14}$ In Germany, scholars did not agree on interpretation. Most authorities applied the lenient approach of the change of water classes. However, in recent years, German courts (of first and second instance), started to follow the stricter approach. In France, the lenient interpretation according to which a water body only deteriorates if it passes to a lower water class was even codified in Article 212-13 Code de l 'Environment. In its answer to this European disharmonism, the Court again starts with an analysis of the wording of the deterioration ban ex Article 4 (1) (a) (i) WFD and it argues that

\footnotetext{
13 ECJ Case C-129/96 Inter-Environnement [1997] ECR I-7411.

14 See for example A.M. Keessen et al, European River Basins: Are They Swimming in the Same Implementation Pool?, Journal of Environmental Law, 22:2 (2010), 197-221. For the German literature see e.g. K. Faßbender, Zur aktuellen Diskussion um das Verschlechterungsverbot der Wasserrrahmenrichtlinie, EurUP 2013, p. 70 with further readings for both opinions in footnotes 11 and 12. The German OvG Hamburg 18 January 2013, 5 E 11/o8, applied a strict view.
} 
this norm and the definition of "surface water status" in Article 2 (17) WFD, too, do not mention the concept of different classes whereas the obligations to improve water status from Article 4(1)(a)(ii) and (iii) WFD explicitly do refer to annex $\mathrm{v}$ and the class concept. From that, the court infers, that deterioration prima facie means any worsening, even within the same class. The Court continues with some systematic arguments which are very convincing. To determine the quality class a whole range of different parameters has to be examined If only one of these parameters falls to a lower class then the whole water body must be assigned to this lower class. Hence, the Court applies the so called "one-out-all-out principle". Since classification of a body of surface water depends on the poorest value of all applicable parameters, (many) other parameters may be much better than the actual qualification of a certain water body suggests. If 'deterioration' would only cover the lowering of a class, the prohibition of Article 4 (1) (a) (i) WFD would be a very weak instrument as all these better parameters could be reduced to the level of the poorest one without getting into conflict with the prohibition of deterioration. Furthermore, waters in the lowest class would be excluded from the scope of the obligation to prevent deterioration of their status. This result would conflict with Article 4 (5) (c) WFD and would furthermore be strange since the regime for these poor waters, which should reserve special attention, would be less strict than that of all other water bodies.

Does therefore each worsening of any parameter for the quality of a surface water result in a deterioration which, even for a short period, is strictly forbidden? Or does this prohibition only apply to a minimum intensity of decline? The German government had argued that only 'serious impairments' 15 would qualify as deterioration. ${ }^{16}$ The Court argues that the effectiveness of the Directive would seriously be hampered in case the no-deterioration requirement would mean that only when all elements of the good status worsen the water body would arrive in a lower status class and that only in this case one could speak of deterioration. That would seriously jeopardize the achievement of the final objectives of the Directive and does not fit in the textual and systematic analysis of the Directive. On the other hand, not every very little decline of one of the parameters of Annex $v$ causes a deterioration. After having stressed that a strict approach has to be chosen and that the threshold of

15 'Serious' is a somewhat debatable translation of the original German 'erheblich' which we preferably would translate with significant or considerable.

16 The same applies for The Netherlands, France, England and Denmark, see A.M. Keessen et al, European River Basins: Are They Swimming in the Same Implementation Pool?, Journal of Environmental Law, 22:2 (2010), p. 211. 
what a deterioration is should be low, the Court decides, without any further argumentation, that a surface water (only) deteriorates 'as soon as the status of at least one of the quality elements, within the meaning of Annex $v$ to the Directive, falls by one class, even if that fall does not result in a fall in classification of the body of surface water as a whole' (point 69 and 70 ). If, however, a quality element is already in the lowest class, any deterioration of that element constitutes a 'deterioration of the status' of a body of surface water.

If we are not mistaken, the ECJ in the end steers a quite strict course, which however is not extreme and as precise as possible to apply. On the one hand not every little decline means deterioration, but only a fall of one of the parameters by one class. That renders it unnecessary to discuss whether there should be some sort of de minimis threshold and what this de minimis threshold should be. On the other hand the Court applies a strict 'one out, all out'-approach. If only one of the parameters falls with one class, the status deteriorates. The Court allows deterioration of all biological quality elements, hydromorphological quality elements and physico-chemical quality elements within a status class without the need to rely on the derogation laid down in Article 4(7) of the directive, unless none of them hits a lower status class. In so far, the court does make reference to the class system although it had ${ }^{17}$ inferred from the wording and the systematic context that the Directive does not make such a link between the deterioration ban and the class system of Annex v.

\section{Consequences for Water Policy and Law}

The most important consequence of the ruling of the Court is that it sheds a far more clearer light on the system and legal meaning of the WFD. It makes clear that the different provisions of the Directive cannot be properly understood in isolation but should be interpreted within the whole system of the WFD. All provisions are interconnected and build up a modern system of water law that tries to combine a need for flexibility, policy discretion and subsidiarity on the one hand and an on-going improvement and effective protection of Europe's waters on the other hand. By emphasising that the overall goals and especially the environmental goals are strictly binding obligations in all phases the Directive contains, the Court choses in our opinion the best way to combine the needs described above. Flexibility remains an important advantage of the WFD. The Member States can partly set their own goals although after inter

17 Point 61. 
calibration. They can focus on the main water problems in their country and choose those measures that are most effective and fit well in the national context. In case there are serious reasons for postposing or lowering goals, the Directive offers numerous possibilities, although under strict conditions.

On the other hand, many Member States will not be amused by some elements in the judgement. The obligations are more binding than many Member States expected or hoped for. Also the fact that environmental objectives should play a role in each phase of the cyclic approach that the WFD takes will lead to changes in regulatory approaches in some of the Member States. It will lead to discussions on what kind of programmatic approach should be designed to meet the requirements of the Directive. In this regard it is important to take a different approach for those water bodies that are already in a good status and those water bodies which do not meet the standards yet. In this respect especially Article 11 (5) WFD is an important provision. It makes clear that as long as the standards are not yet met a link between quality standards, authorizations for projects and concrete decisions should be stronger than in those cases where the status of a water body is good. Even when all measures are combined within a programme of measures, individual authorizations should be revised in case the requirements of Article 4 are not met. Therefore, each programmatic approach should take into account specific circumstances of the water body regarding scale, natural characteristics and human impacts. It will make a difference whether the quality status of the river Rhine has to be improved or whether it concerns an isolated lake or small water body. On the other hand, most Member States will prefer to develop legislation applicable to the whole country or to large river basin districts. Because the WFD puts a strong emphasis on the goal to be achieved and requires that the causes of water pollution or ecological degradation will be tackled at the source of the problem, the Member States have less flexibility in their programme of measures than some may have hoped for. The Dutch approach for example relates the environmental objectives only to the establishment of water plans, in which the programme of measure is included. There is no formal link between environmental objectives and water quality standards and the authorisation of projects or concrete licenses in the way that an authorization cannot be granted if it would lead to deterioration of a water body. There is certainly no link between water quality objectives and decisions taken in other policy fields like urban planning, nature conservation, environment, agriculture or infrastructure. The Dutch Parliament agreed when implementing the WFD that the WFD should not cost the agricultural sector any money. It is difficult to keep this approach alive. Recently the Parliament asked for the opinion of the Minister of Environment and Infrastructure what the consequences of the Weser -case 
will be for the Dutch approach in environmental matters and in water management particularly. ${ }^{18}$

Another issue concerning the judgement of the Court is that economic considerations can only be taken into account when a Member State relies on one of the exemptions in the WFD. Again in Dutch policy plans we can see that environmental objectives and economic considerations are weighed out without explicitly relying on the exemptions of the Directive. This means that water authorities should have a close look at river basin management plans and programmes of measures to check whether they follow the system of the WFD as explained by the Court. This should be done before the second round of plans and programmes are finalised, which have to be taken care of before 22 December 2015. In case authorities refer to policy documents, plans or programmes (within or outside a specific programmatic approach) they should check whether, on the basis of Article 4 (7) WFD, these documents may serve as an appropriate motivation for concrete decisions in the field of water management and beyond. We are not familiar enough with all the specific elements of the legislation implementing the WFD in other Member States, but we expect that the judgement will lead to adjustments in the legislation of other Member States as well. It will differ per Member State which element of the judgement asks for adjustments of the national legal framework.

Environmental quality standards are not only used in water law, but are common in several areas. The most well -known examples probably are the air quality standards stemming from Article 13 Directive 2008/50/EC on ambient air quality and cleaner air for Europe. Article 12 entails a 'stand still requirement' similar to the requirement of no deterioration of the WFD. Another, perhaps less obvious, example are the requirements of Articles 3 (1) and 6 (2) Habitats Directive (Directive 92/43/EC). According to Article 3 (1), the Habitats Directive aims to realize an ecological network which shall enable the natural habitat types and the species concerned to be maintained at or, where appropriate, restored to a favourable conservation status. Article 6 (2) urges the Member States 'to avoid, in the special areas of conservation, the deterioration of natural habitats and the habitats of species as well as disturbance of the species for which the areas have been designated, in so far as such disturbance could be significant in relation to the objectives of this Directive'. This case

18 Second Chamber of Parliament, 2015-2016, nr. 2015Z17417, 25 September 2015. 
note does not offer the room to discuss the consequences of the Weserjudgment for the interpretation of other quality standards and stand still clauses in European environmental law. It will be interesting and worthwhile to reflect on this question. Such an examination will have to be based on a thorough analysis of the similarities and differences of different EU environmental quality standards.

The role of quality standards cannot be underestimated in the field of environmental law. They translate overarching and normative environmental objectives in more or less measurable objectives which play a role in policy making, planning and authorizations for projects and concrete decisions. It is of utmost importance how these quality standards are designed. What wordings are used, are they numerical or more descriptive, what legal status do they have, should they be regarded as obligations of best effort or as obligations of result, what is their influence on the choice of policy approaches, should they be taken into account in every phase of the policy process or only apply to a non-binding plan or policy document? The ruling of the Court balances between flexibility for the Member States and enforceable obligations to improve the effectiveness of environmental law. Choosing this approach seems to be a good approach. Strict and nonflexible obligations following from each provision of the WFD would increase the enforceability but also the administrative burdens of the Member States and would decrease their room for policy discretion. On the other hand, a Directive with mainly open, flexible and only procedural obligations would hamper the effectiveness and enforceability of the Directive. Choosing for strictly binding environmental obligations combined with a large amount of policy discretion seems a workable approach for more environmental Directives than only the WFD. 